\title{
Managing Democracy in Social Movement Organizations
}

\author{
AUSTIN CHOI-FITZPATRICK \\ School of Public Policy, Central European University, Budapest, Hungary
}

\begin{abstract}
Leaders are crucial to social movement mobilization and maintenance. They often experience conflict between a value for inclusive engagement and a sense that they are moving efficiently toward their organizations' goals. This study draws on a multisite ethnography to suggest two mechanisms through which leaders may resolve this conflict: staging (manipulating organizational procedures) and scripting (using language to reinforce these procedures). Resolving tension in this way often leaves the leader in control of organizational processes and outcomes, and has the unintended effect of stifling the actual process of democratic participation. This study emphasizes the culturally embedded inertia of the democratic ideal and highlights a particular set of tactics for democracy management. It is proposed that these mechanisms might be helpfully applied to a growing literature on inclusive engagement in contemporary associational forms as well as a range of other institutional contexts.
\end{abstract}

KEY WoRDS: Democracy, culture, norms, oligarchy, organizations, inequality, strategy

Organization is often thought to be a process that terminates in elite control. Yet leaders of small social movement groups are often torn between institutionally embedded demands for organizational efficiency and culturally embedded values for inclusive engagement. Social movement scholars note a steady emphasis on inclusion and consensus in the groups they study (Ferree \& Martin, 1995; Polletta, 2002, 2006). Groups preferring inclusive strategies often lack political and economic resources, relying instead on the strength of their claims and the validity of their organizational processes to establish and maintain legitimacy (Rothschild \& Russell, 1986). However, rising expectations - from both individual members and the public - pressure most organizations to demonstrate efficiency (Meyer \& Rowan, 1977).

I draw on ethnographic fieldwork to suggest that movement and organization leaders may experience countervailing pressure between a culturally embedded value for inclusive engagement and institutionally embedded demands for organizational efficiency. Although this sort of tension was popularized decades ago (Meyer \& Rowan, 1977), most of the work in intervening years has focused on oligarchy in non-bureaucratic organizations (Hallett, 2010; Leach, 2005). Ethnographic fieldwork thus provides an opportunity to better specify the ways broader cultural values shape group contexts, which in turn shape what is locally possible (Eliasoph \& Lichterman, 2003).

Correspondence Address: Austin Choi-Fitzpatrick, School of Public Policy, Central European University, Nador Street 9, Budapest 1051, Hungary. Email: choifitza@ceu.hu 


\section{A. Choi-Fitzpatrick}

This article's primary contribution is the observation that leaders may address the tension between inclusive engagement and organizational efficiency in symbolic, rather than practical, terms. Symbolic resolution comes when a leader is able to achieve a veneer of consensus in which 'each participant conceal(s) [his or her] own wants behind statements which assert values to which everyone present feels obliged to give lip service' (Goffman, 1959, p. 8). This veneer is achieved through the twin mechanisms of staging and scripting, mechanisms that serve to reinforce rhetoric while undermining action. By staging I mean the manipulation of organizational procedures (especially how meetings are run) by leaders to enhance the appearance of a particular commitment (here democracy and inclusive engagement). By scripting I mean the ways language is used to create, reinforce, and repair a sense of commitment. This approach is in line with that adopted by Benford and Hunt (1992), who define scripting as 'interactionally emergent guides for collective consciousness and action ... [that] provide behavioral cues when unanticipated events arise' (p. 38) and staging as involving 'the maintenance and expansion of an organization's capacity to communicate their ideas about power' (p. 43). A critical task for organizations, therefore, is the 'staging of performances that are consistent with the script' (p. 43), a process which requires the use of correct cultural symbols.

Understanding this staging and scripting process in certain non-bureaucratic organizations expands our appreciation for the complexity involved in fostering the sort of open and democratic discussion valued by many social movement actors. The existence and use of these strategies suggest several contributions to scholarship on social movements. Specifically, it suggests that while organizations may experience pressure to get the job done, democratic values and expectations are quite robust. Qualitative data also suggest the extent to which organizational strategies and goals are drawn from repertoires that are embedded in broader organizational and sociocultural norms (Clemens, 1993). In the final analysis, this study provides evidence of the way appeals to culturally embedded forms of legitimacy may frame and constrain oligarchic tendencies and elite control.

\section{The Iron Law and Cultural Repertoires}

The organizational repertoire for many social movement organizations involves normative commitments to ensuring broad representation and voice for traditionally marginalized individuals and groups (Bordt, 1997; Smith, 2008). This value for participation and inclusion can be seen in recent scholarship on both organizational forms (Baiocchi, 2005; Baiocchi, Heller, \& Silva, 2008; Polletta \& Lee, 2006) and styles of leadership (Aminzade, Goldstone, \& Perry, 2001; Diani, 2003). Arguing that participatory discourse is the foundation of democratic legitimacy, Polletta and Lee (2006) highlight a widespread interest in democratic organizational forms and processes. Such commitments are difficult to sustain, especially if bureaucracy formalizes leadership in ways that engender oligarchy (Ferree \& Martin, 1995; Freeman, 1972; Giugni, McAdam, \& Tilly, 1999; Lee, 2007). Efforts to balance formalism and collectivism have met with various levels of success (Bordt, 1997; Ganz, 2000; Rothschild \& Russell, 1986) and have been the subject of sometimes contradictory studies (Milkman \& Voss, 2004; Rucht, 1999; Voss \& Sherman, 2000).

Leaders' impact on democratic participation within social movement groups has generated broad and sustained interest (Baiocchi, 2003; Bourdieu, 1991; DiMaggio \& Powell, 1983; Michels, 1915/1962; Mouffe, 1996). This work suggests the 
professionalization of leadership that accompanies bureaucratization has several consequences for social movement groups and organizations (Staggenborg, 1995). Although professionalization is usually required as movement groups grow (McCarthy \& Zald, 1973), it often leads to a decline in innovative practices among institutionalized social movement leaders (Staggenborg, 1988), while also facilitating Coalition work and sustaining movements through seasons of dormancy (Reger \& Staggenborg, 2006; Taylor, 1989). Stronger leadership and better strategies, both internally and externally, help attract participants and achieve movement goals while reducing a sense of grassroots involvement (Tait, 2005, p. 198).

Since bureaucracy was assumed to be the most effective organizational form, Michels expected it to be adopted by institutions regardless of competing normative commitments: 'democracy is only a form of organization and that where it ceases to be possible to harmonize democracy with organization, it is better to abandon the former than the latter' (1915/1962, p. 35). From this 'organic necessity' came the iron law - whoever says organization says oligarchy - a condition inevitably affecting 'every organization.' Michels' argument rests on the combination of two factors: inevitability ('organic necessity') and total institutional coverage ('every organization').

Michels' hypothesis has been the subject of sustained debate (recently, see Ganz, 2000; Stepan-Norris \& Zeitlin, 2003), much of it rooted in the difficulty of identifying and articulating the contours of the slippery slope lying between democratic ideals and oligarchic practices (Leach, 2005). My interest lies not with the debate about democracy per se, but with the underlying tensions and mechanisms that the debate reveals. ${ }^{1}$ Leaders cannot simply abandon democratic practices when constrained by organizational demands, nor do they necessarily want to. The principle underlying this observation was first advanced by Meyer and Rowan, who observed that 'rules are classifications built into society' and must therefore be followed, even if conformity to institutionalized rules 'conflict[s] with the logic of efficiency' (1977, p. 341). Importantly for this study, they argued that organizations adopting these rules 'maximize their legitimacy and increase their resource and survival capabilities' (p. 352) but 'fail when they deviate from the prescriptions of institutionalizing myths' (p. 353).

The scholarship on progressive/left social movement groups suggests their key 'institutionalizing myths' are something closer to a democratic ideal of representation and inclusion than the logic of efficiency (Epstein, 1991; Polletta, 2002). Arguing that democratic organizational forms are drawn from a repertoire of contemporary American political culture, Clemens (1993, p. 758) writes: 'models of organization comprise both templates for arranging relationships within an organization and sets of scripts for action culturally associated with that type of organization.' This cultural repertoire constricts the speed and shape of the tendency identified by Michels. Legitimacy is socially and culturally embedded. Thus, hierarchy may be considered a more efficient form of organization (cf. Clemens, 1993), but it is not always the most socially accepted way to realize organizational goals.

Clemens drives home a point that Michels missed: participants expect the leadership will be democratic and this expectation for democratic inclusion must be taken quite seriously, as its roots lie both within the organizational or group culture, but more deeply in politics and culture (Polletta, 2002, pp. 213, 217). Models of organization are drawn from cultural repertoires that have a great deal to say about which forms are "culturally or experimentally available' in practical terms, and culturally legitimate and acceptable in 
strategic terms (Clemens, 1993, p. 758; Swidler, 1986; Taylor \& Van Dyke, 2004). Furthermore, the organizational repertoire may provide sets of scripts for culturally sanctioned action.

The implication is that organizations must get their models 'right.' This involves more than ensuring organizational success through the adoption of increasingly efficient processes. It also 'signals identity and delimits alliances' (Clemens, 1993, p. 771) and plays a significant role in determining whether an organization will be considered legitimate in its claims, both within the social movement field and in larger political and cultural spheres. The process of 'getting it right,' Clemens argues, involves a tremendous amount of cultural work as 'models of organization are not only conventions for coordinating action but also statements of what it means for certain people to organize in certain ways for certain purposes' (p. 775). Benford and Hunt (1992, p. 38) take the implications a step further, arguing that social movements themselves are 'dramas in which protagonists and antagonists compete to affect audiences' interpretations of power relations in a variety of domains'. It is critical that an organization's performances (Gardner \& Avolio, 1998, p. 44) resonate with broader, culturally accepted repertoires. Although this article focuses on the implications for progressive associations, there is the real possibility that staging and scripting is used to generate the appearance of compliance with other norms.

In their original work, Meyer and Rowan (1977) suggest 'decoupling' as a shortcut to the hard work of actually 'getting it right.' Organizations, Meyer and Rowan argue, 'can resolve conflicts between ceremonial rules and efficiency' (p. 356) through decoupling, which is 'the ability to coordinate things in violation of the rules - that is, to get along with other people' (p. 357). Decoupling benefits organizations because it 'enables organizations to maintain standardized, legitimating, formal structures while their activities vary in response to practical considerations' (p. 357). The ethnography that follows demonstrates one set of strategies for 'getting it right' such that the conflicts between rules and efficiency appear to be resolved.

\section{Methods and Data}

This study responds to recent calls for social movement scholars to focus on organizations as comprising actors and events - as social spaces - rather than as actors within particular events (Clemens, 1993; Minkoff \& McCarthy, 2005; Polletta, 2002, p. 225). Voss and Sherman (2000) suggest this approach illuminates movement dynamics beyond contentious events and political opportunities (e.g. Boekkooi, Klandermans, \& van Stekelenburg, 2011). In keeping with their challenge, I investigate similar phenomena across two groups working on social change. Table 1 highlights several key similarities and differences between these two organizations.

This ethnographic undertaking draws on 18 months of participant observation to illuminate the role of democratic organizational forms in two groups in the Midwest. These two organizations share a number of key similarities. They were selected because they were the largest and most active non-union movement actors working for progressive causes in the region. A study drawing on participant observation in unions in the area older organizations with clear lines of command mobilizing blue-collar workers in declining industries - perhaps would have identified trends unique to more hierarchically organized and better funded organizations. Thus, my selection of two voluntary, 
Table 1. Key similarities and differences across the Coalition and Taskforce

\begin{tabular}{|c|c|c|}
\hline \multicolumn{3}{|c|}{ Similarities } \\
\hline Membership & Voluntary & \\
\hline Status & Non-profit & \\
\hline Objectives & $\begin{array}{l}\text { Challenging city council to } \\
\text { pass ordinance }\end{array}$ & \\
\hline Staff & Unpaid staff & \\
\hline \multirow[t]{3}{*}{ Regional scope } & Citywide & \\
\hline & \multicolumn{2}{|c|}{ Differences } \\
\hline & Taskforce & Coalition \\
\hline Goal setting & $\begin{array}{l}\text { Agenda set locally, by } \\
\text { engaged members }\end{array}$ & $\begin{array}{l}\text { Agenda set externally, by } \\
\text { regional office of community } \\
\text { organizing entity }\end{array}$ \\
\hline Leader experience & $\begin{array}{l}\text { Extensive organizing experience from } \\
\text { the } 1960 \text { s onward }\end{array}$ & Newly trained organizer \\
\hline Org. philosophies & Fundamentally humanist & Religious conviction \\
\hline Key supporters & Secular citizens & Religious churchgoers \\
\hline Local government links & Long-term and familiar & Thin and formal \\
\hline Largest event & $\sim 200$ attendees & $\sim 2000$ \\
\hline Membership & No formal & No formal \\
\hline Meeting size & $5-8$ & $10-15$ \\
\hline Founding date & 2006 & 2008 \\
\hline Language & English & English and Spanish \\
\hline
\end{tabular}

progressive, non-profit organizations with unpaid staff, and local objectives (challenges to city council) has an impact on my findings.

This study also focuses on civic activity as it unfolds within a community context (Sampson, McAdam, MacIndoe, \& Weffer, 2005). Both organizations fit Sampson et al.'s generous conceptualization of social movement actors as entities that 'marry the metaphorical bowling league to civic action' and pursue 'hybrid collective events' which "typically combine protest-like "claims" for change with civil society "forms" (2005, p. 681). Neither group was formally registered as a non-profit, yet each possessed organizational infrastructure in keeping with most small non-profit organizations. Both engaged in ideologically structured action (Zald, 2000): the Coalition had focused nearconfrontational meetings with political leaders, whereas the Taskforce participated in picket lines and other forms of collective action.

\section{Community Economic Taskforce}

The organizations' key differences can be seen in an examination of the organization's objectives and leadership. The Taskforce's objectives are modest and geared toward improving and reforming the existing political order. During this fieldwork, the majority of their energy was focused on holding local elected officials accountable for the expenditure of tax revenues. This study draws on data from the group's monthly community meeting (with an open forum for 50-60 attendees) and biweekly steering committee meeting (8-10 members). Meetings occur in community spaces donated by a local non-profit and a nearby university. Meetings were predominantly attended by middle-class Anglo community 
members. Issues were selected by the group's steering committee, often in collaboration with the participants in the group's monthly community meeting.

The Taskforce's leadership was provided by Gretchen, an outspoken community activist in her sixties. Gretchen came of age as a working class Anglo in the rust belt of the 1960s, and her political memory was marked by her involvement in the civil rights movement and local labor initiatives. Gretchen shared the leadership role with her husband, Tom, a local professor and outspoken advocate of government transparency and a 'democratic process that draws on concerns and energies of all.' Together they founded the group to address issues related to economic injustice in the region. ${ }^{2}$

\section{Faith-Based Coalition}

The Coalition's objectives were broad and were said to have arisen from within its core constituency of local Protestant and Catholic congregations. Over the course of the fieldwork, the Coalition's key working group and the primary site for this study - the Civil Rights and Immigration Committee - was focused on supporting a city ordinance on racial profiling, an effort which required the participation of both black and Latino community members. The study draws on data from the group's monthly CRI Committee meetings (10-15 members) and is complemented by data from the group's larger, citywide events (around 2000 participants). The committee's meetings took place in space donated by an active Catholic parish and comprised a more or less equal number of Anglos and Latinos. ${ }^{3}$

The Coalition's leadership, at the committee level, was provided by Helen, a softspoken Anglo woman in her sixties. Helen took the leadership of the committee after her congregation became involved in the Coalition, and to the best of my knowledge, it was the first time she had served in such a position. Unlike Gretchen, the experienced leader of the Taskforce, Helen lacked a background in advocacy or activism. ${ }^{4}$

A number of additional differences can be identified in addition to the organization's objectives and leadership. The Coalition's agenda, even at the committee level, was set externally by the regional office of the community organizing entity, a fact which contrasts sharply with the Taskforce's agenda, which was set locally by engaged members. The fact that the Coalition's key committee was led by a newly trained organizer whose job was to implement initiatives that had been identified at levels above her had a significant impact on the trajectory of some meetings, seen in the qualitative data. This can be contrasted with the Taskforce, where the steering committee (and the community participants, to a lesser extent) was absolutely critical in decision-making and agenda setting.

In the Coalition, differences in language played a key role in complicating attempts to perform democracy, as seen in the qualitative data below. Other differences seemed to not have any impact, such as varying organizational philosophies, the level at which agendas were set, the type of key supporters, and the quality of local government links. Although each of those factors contributed to the nature and flavor of the groups, I do not have any reason to believe they resulted in theoretically salient patterns. The same is true for meeting and event size. The Coalition did not secure victories regarding the city ordinance, despite the fact that they organized an event that was approximately 10 times larger than the Taskforce's largest event. Both groups were relatively young and neither had a substantial annual budget - indeed for both the bulk of the monies went to single mobilizing events. 


\section{Data Collection}

Participant observation provided data on planning meetings, public gatherings, and political actions. This involved attending between two and five events per month. This length of time, and frequency of attendance, provided an opportunity to observe the following: the emergence and discussion of multiple issues; the implementation or denouement of specific topics, events, and strategies, and the ingress and egress of new and old participants. Baiocchi (2003) has observed that participant observation gives a researcher the opportunity to better discern 'questions of meaning, intent, purpose, and implicit rules' (p. 59). This approach helped me to better recognize the complexity of leaders' decision-making processes.

When I first entered the field, I conducted preliminary interviews with the leaders of both groups. These early unstructured interviews helped established rapport while providing me with an initial sense of how these groups described their organizational history and framed their current efforts. As the broader contours of the study took shape, I conducted a number of follow-up interviews with the same leaders in an effort to explore their own perspectives and opinions on decision-making. As I was exiting the field, a final round of semi-structured interviews conducted allowed me to follow up on hunches developed during participant observation, in particular regarding the complex interplay between inclusion and efficiency. Interviews with leaders complemented and clarified data gleaned from participant observation.

\section{Managing Democracy}

The qualitative data that follows draw on particular moments in both the Coalition and the Taskforce in order to illustrate: (i) each group's commitment to democratic processes, (ii) the work of creating an inclusive and representative-seeming space, and (iii) the strategies used when the appearance of this commitment is jeopardized. I find specific patterns in the strategies leaders deploy in an effort to manage the democratic process. I refer to these strategies as staging and scripting. By staging, I mean leaders' manipulation of organizational procedures to enhance the appearance of a particular commitment (to democracy, in this case). Staging represents what Lukes' (2004) referred to as power's second face: the use of power to effectively remove some topics from discussion. The term scripting is used to describe the ways in which language (and other symbolic communication, such as votes) is used to pay lip service to the idea of the particular commitment (i.e. democratic participation) or restrict participation outright. I find scripting can be deployed in order to reinforce staging efforts, sanction inconvenient input, end conversations, and transform scripting issues into staging issues. This transition of scripting to staging can be seen, for example, when a leader moves a decision or discussion from an open community forum to a closed organizational forum if the topic does not support strategic organizational goals. ${ }^{5}$

At times, meeting participants may make a scene. Scenes are situations 'in which an individual acts in such a way as to destroy or seriously threaten the polite appearance of consensus' (Goffman, 1959, p. 210). Appearance is best projected through the establishment of a democratic-seeming organizational procedure (staging) and best maintained through democratic talk (scripting). On the surface, the use of staging and 
scripting strategies are so commonsensical that they might be dismissed out of hand, or mistaken for malevolence or incompetence.

\section{Staging and Scripting Inclusive Engagement in the Taskforce}

It can easily be seen that both groups value and are mobilized to secure inclusive engagement. In the Taskforce, a preliminary agenda is circulated to the group one week in advance, with an open invitation to contribute. At one of the Taskforce's community-wide meeting, a member of the group's leadership told those assembled that the community 'needs democracy. Of course when I say democracy I mean not just going to the polls every four years ... I mean the active participation of citizens in their government and in the making of their society.' While this is clearly a call to participation and engagement outside the Taskforce, he went on to highlight the significance of 'the democratic process within the [Taskforce] to develop questions for the candidates on issues of economic development.' This value for the use of democratic processes in the Taskforce is underscored by his definition of the democratic process as 'draw[ing] on concerns and energies of all' (emphasis added).

This commitment to inclusive engagement in the Taskforce is emphasized by the frequent use of the term consensus, as well as frequent efforts by Gretchen, Tom's wife and the leader of the group's Steering Committee, to 'open the table up to everyone's perspective.' Invariably such invitations were met with uncomfortably long periods of silence, followed by Gretchen's playful chiding. In this silence, the message was clear: democratic input trumps organizational efficiency.

In the Taskforce, the vote played a significant role in the process of setting the stage for a decision that 'drew on the energies of all.' The complexity of using a vote to balance input and efficiency was noted by Janet, a Taskforce member who later told me that 'in [Gretchen and Tom's] hearts they really want democracy - so we take votes. But I know which issues won't get taken up regardless.' Janet points out that while all issues are voted on, not all are acted on. People are asked to raise their voices symbolically, through the act of voting, but these votes are not necessarily connected to whether the issue is actually taken up by the Taskforce.

\section{Staging and Scripting Inclusive Engagement in the Coalition}

Helen, the Coalition's facilitator, does not open the agenda-setting process to general membership, though the agenda is consistently translated into both English and Spanish. Nevertheless, great efforts are made to highlight the importance of democratic engagement. Leaders emphasized that 'democracy doesn't end at elections,' while Helen gathered volunteers for a 'listening initiative' to bring the community's voices to their elected officials. This value for broad representation extended to the group's significant Spanish-speaking membership as participants were reminded that '[this city] and our democracy have multiple languages.'

This value generated participation that strained the leader's ability to control the content and pace of meetings. At the end of most meetings, Helen would ask each member to sum up in one word how they felt. 'Anxious,' 'hopeful,' 'expectant' participants would answer, giving Helen an opportunity to ask follow-up questions of select participants ('Why do you feel hopeful?'). This process opened the floor to participant voices, but not in a way 
that affected the agenda, or the meeting, which had just finished. In both cases, the stage a strategically sanctioned space - was set for the incorporation of participants' voices. Yet this inclusive space remained separate from the decision-making process. While participants recognize the balancing act required of a leader (Janet knows 'which issues won't get taken up'), and they remain supportive. This appearance, however, may be interrupted by a scene.

\section{Making a Democratic Scene: Debate Without Consensus in the Taskforce}

In one of the Taskforce's monthly community-wide meetings, held immediately prior to a local election, Gretchen announced to the group that they would together choose five questions for the candidates. The answers would be chosen, Gretchen indicated, 'by consensus. ${ }^{6}$ With this, she divided the room into smaller groups so each could select several questions for the candidates. I watched with interest as each group finally reported back and, after some discussion, their feedback was tallied. All participants then gathered around this aggregated feedback as Gretchen initiated a second round of discussion to narrow the selection.

Most items met with broad-based agreement in the form of physical and verbal feedback and a natural cycle of affirming comments, questions, and answers, all followed by a lull in conversation - a lull which I have here interpreted as a broad and significant satisfaction with the process and the conclusion. Not every point generated such satisfaction, however. A question on tax incentives - the Taskforce's central issue - inspired more fervent and varied discussion. From the murmurs of dissent, it soon became clear that participants were not satisfied with the issue as presented. The apparent desire to continue the vibrant, and potentially lengthy, discussion was met with Gretchen's seemingly even-handed and level-headed suggestion that the group 'not debate this, let's come to an agreement.' She proceeded to take a vote. The vote only served to illustrate, in somewhat starker terms, what the truncated discussion had already suggested: there were many varied perspectives in the room. Reaching Gretchen's impromptu benchmark (consensus) would require additional, time-consuming discussion.

Yet the vote was taken as a concluding act after which Gretchen recommended the group 'move on to the other issues,' effectively delegating the decision back to the smaller steering committee, which she chaired. Having clearly stated a value for the trappings of a democratic process (consensus, agreement, soliciting input, votes), Gretchen established and reinforced the appearance of a commitment to inclusion and engagement, as realized through widely accepted democratic forms. In this way she appeared intent on engineering 'a convincing impression' that the will of the people was being realized in the process, using a critical component of the democratic process - the vote - to close debate.

This conclusion to the discussion, however, was met with an apparent lack of democratic satisfaction. Gretchen had emphasized the importance of a democratic process through her stated hope that the group could 'do this by consensus,' but abandoned the effort when it appeared the consensus process would conflict with the efficient and desired resolution of a key issue. I argue this recommendation can be interpreted as a shift from the failed scripting strategy to a more stable (but less respectable) staging strategy. I say 'less respectable' as the compositional, spatial, and temporal shifts required by most staging strategies (steering committee meetings are held with fewer people at a separate place and a different time) may be interpreted as a move away from more open and inclusive forms 
of the democratic process. This resolution left me with the impression that time would be made to continue discussion of the topic - an impression that may have been shared by others. Yet the issue never reemerged. I did note, however, at the next community meeting, and indeed at the steering committee meetings between, that the issue preferred by Gretchen remained intact, as originally conceived, unaffected by the flurry of discussion solicited from the group.

This staging strategy effectively used a Taskforce discussion to launder a committee decision. The issue, apparently already settled in the leader's mind, was brought to - and taken from - the table, unscathed by the community's input. This is not to say the steering committee made a poor decision, but instead to highlight the significant scripting and staging required to secure both a decision and a democratic-appearing performance. The theoretical argument I am extending from Goffman (1959, p. 251) suggests Gretchen's behavior - intentionally or not - served to '[engineer] a convincing impression' that the standards of democratic involvement were being realized, rather than 'the moral issue of realizing these standards.' In subsequent conversations, Gretchen expressed a certain ambivalence about events like this, musing: 'It seems like we always have lots to do, but what that does is to limit certain people.' This concern is underscored by her candid recognition of the scripting and staging strategies identified in this analysis:

You have to have structure. I believe in structure, I'm not an anarchist ... there have been times when people start ... [talking] ... and they're single issue, they have blinders, so sometimes you have to cut them off a little bit.

Interview data suggest Gretchen's awareness of, and concern for, this role as she avoided more open forms of democracy in favor of actions that would more effectively accomplish strategic organizational goals. As one active member, Janet, pointed out to me, 'There are lots of topics that we don't get to dwell on because they're not on somebody's agenda, and that's too bad. It's not that they're not as important but [Gretchen] tends to talk quite a bit and this often means there are times we don't get to give everything the attention it deserves.' She continued, pointing out that Gretchen and Tom 'are all about democracy and everyone having a voice. But if you raise an issue that they don't like, it won't go anywhere. They will take a vote and everything, but nothing will happen.' Insightful and loyal, Janet represents the quintessential member's voice. One can conclude that the decision to stay rather than leave - loyalty over voice, if you will - despite realizing that 'nothing will happen' adversely affects her commitment while also reintroducing her as a team player in the group's performance of democracy. In her case, as in others, loyalty results in both silence as well as a reaffirmation of the 'movement's constructed definitions or emergent norms' (Benford \& Hunt, 1992; Turner \& Killian, 1993).

\section{Making a Democratic Scene: Closing Conversations with Prayer in the Coalition}

Although a vote was used to curb decision-making conversation in the Taskforce, voices were similarly silenced by prayer in the Coalition's issue group. In this example of scripting, Helen invoked prayer in much the same way Gretchen used the vote. On two separate occasions, conversations in Spanish generated such excitement that the translator was no longer able to keep up. One of the only slivers that came out in English was one 
man's observation that Latinos don't get involved in the group, or soon exit, because 'they don't want to waste their time and they'll get nothing out of it.' This observation - critical to the group's efforts to retain Latino involvement in the discrimination ordinance - was passed over by Helen. Rather than asking for translation of what would appear to be a significantly vibrant conversation that included the voices and insights of many, Helen's physical energy shifted, her body language indicating that the meeting had now come to a close. Yet the meeting's closure did not stick, as the energy in the room had spilled outside of the meeting's format - off the stage, if you will. The appearance of consensus had been violated and the Latino members - many speaking at once - were now causing a scene in Spanish. In response, Helen adopted a more assertive approach that blended both strategies, asking the participants to bow their heads so she could close the meeting in prayer.

This request can be seen as the traditional religious gesture of physically bowing and as also resonating with the humble posture implicitly requested of Latino participants in this and other meetings. Thus, the vibrant discussion that included many voices can be interpreted as the unbowing of the head, the unanticipated emergence of participants as political in this inclusive space. Since the meeting's format, agenda, and leader lacked the real capacity for this involvement, prayer was deployed as a simultaneous staging and scripting strategy (invoking speech and schedule) with the effect of silencing these untranslated voices and ending the meeting. This was not the first time Helen had ended a discussion with prayer. An earlier meeting met a similar fate, despite the emergence of a vibrant and unprecedented conversation about race and ethnicity among the group's few African American members and the Latino majority - a conversation engaged enthusiastically by the entire group.

The spontaneity and enthusiasm with which these conversations emerged suggest that a lack of engagement by this community was due not to reticence, but instead to the broader issue containment strategies deployed by the group's Anglo leadership. This is borne out by a committee meeting led by Maria, a higher status Latina organizer, late in my fieldwork. Her presence seemed to open the space as contributions from Spanish-speaking members were solicited and sustained with an unprecedented fluidity. The meeting itself seemed much more open, convivial, and energetic and left me with an even clearer sense that each of the committee members, including the heretofore silent Latinos, had an opinion and a voice that might not have been shared if not for Maria's presence. Indeed, in the Coalition these decisions were never brought to the committee in the first place. Instead, decisions were made in advance by leadership. In doing so, the organization's agenda was advanced, opposition for participant engagement was reduced, and a scene was avoided. Paradoxically, this lack of participant engagement was met at every turn by efforts to encourage and reassure Latinos of the importance of their participation.

At the organizational level, this fieldwork suggests participants played only a small part in the original selection of the Coalition's key issues. As Helen told me in an interview, selecting issues 'is not a neat and tidy process, it's a lot of back-and-forth and flailing around the issues that people come up with.' Angelica, the group's Latina translator, suggested that while some 'back-and-forth' may have occurred within the community, the issue committee's specific demand, a city ordinance on racial profiling, had been chosen by four people: the group leaders and an organizational representative from a larger city in the region. Indeed, the nature and importance of the committee's primary issue is explained to the predominantly Latino participants in each and every meeting, suggesting 
participants are not providing the core energy around this issue but instead fill some other role. ${ }^{7}$ Most meetings began with an explanation, translated into Spanish, of the group's raison d'être, explaining that the group's focus on anti-discrimination legislation benefited 'all of us.' Once again, participants were asked to imagine they played a role in the democratic process that they were unable to engage.

\section{Discussion}

Fieldwork suggests the simultaneous pressure for leaders to practice both inclusion and efficiency may lead to particular behavioral patterns that have the effect of avoiding input and stifling debate. In this article, I set out to document instances in which both organizational form (staging) and talk (scripting) are mobilized in such a way that the final effect is the 'ability to coordinate things in violation of the rules.' For example, individuals are frequently invited to contribute their perspectives in venues where decisions are not made and where mechanisms for implementation do not exist.

A successfully set stage requires only the faintest scripting efforts. If the organizational structure, meeting format, and marginalia appear democratic, talking about the group's democratic values might not be necessary. Should a scene emerge, however, this talk - of democratic commitment - may be deployed immediately. Should this effort fail to curb dissent, staging may again be deployed, here in the form of meeting closure. This decoupling - the ability to coordinate things in violation of the rules - helps leaders to pursue goals without appearing to violate norms.

Although the process of staging and scripting the appearance of inclusive engagement in the service of organizational efficiency may sound harmlessly disingenuous, it can have significant impact. Two outcomes are of particular interest: (i) the stifling of popular and substantive discussions and (ii) member attrition. Concluding a vibrant discussion of tax incentives in the Taskforce precluded the sharing of diverse perspectives, the development of new ideas, and the identification of common ground. In the steering committee, open discussion met a similar fate, again minimizing the amount of serious attention the organization's leaders could pay to this issue. Here, a democratic act (the vote) and a spiritual act (prayer) were used as tools to curtail conversation and debate.

The long-term impact of this approach is suggested by Janet, who pointed out that as an African American attending the group's community-wide meeting for the first time, 'I looked around and there were only ten African Americans there and they were talking about me and what they could do for me, but I wasn't even there' (emphasis added). This lack of personal representation also extends to individual understandings of the group's efforts since 'the beneficiaries might not know [the Taskforce's] issues: social justice and democracy.'

Likewise, a lack of information about the American political process, and fear of contemporary immigration policies have kept many Latinos from engaging politically (Martinez, 2005; Michelson, 2005; Voss \& Bloemraad, 2011). Closing this space to their participation - whether through staging or scripting - closed an avenue for both solidarity and political participation. In fact, in the Coalition open and fruitful dialogue followed the lone instance in which a Latina led the meeting. This instance suggests three things. First, it seems clear leadership style (and perhaps organizational culture) was significant in shaping organizational dynamics. Second, it points to the complex interplay of language and ethnicity - the discussion led by a Latina leader was more energetic and enthusiastic. 
Third, it suggests a simple remedy to the Coalition's efforts to retain and recruit Latino members. Yet, this was an isolated instance and for the most part, Latino members' issues went unrepresented and little effort was made to explain the Coalition's work to heavily recruited newcomers. As a result, few members understood the issue at hand, and even fewer decide to attend meetings regularly. Helen, the group's monolingual Anglo leader, suggested that members of the community are young, busy, and the issue promoted by the group 'might not be their issue.' Angelica, the translator, found the reasons to be deeper, pointing out that while this might not be their issue, Latinos did not understand what was happening in meetings and 'it's not their space.' This is particularly poignant considering the fact that the issue group's meetings are held in a predominantly Latino church within a predominantly Latino community. ${ }^{8}$

It is not surprising that a marginalized and racialized minority would be reluctant to engage in formal political processes like those pursued by the Coalition (Bourdieu, 1991). It is curious, however, that while the organization's planning meetings are attended by Latinos, Anglos, and the occasional African American, the program and conversation are dominated by the group's Anglo participants. What would otherwise be an opportunity for camaraderie and socialization within the Latino community is instead a long, quiet meeting. At first blush, it appears that the process requires only a limited sort of engagement from its participants and putative beneficiaries - a supporting cast (Benford \& Hunt, 1992, p. 40). The Coalition's strategies required Latino participation and 'buy-in.' More important than Latino voices on the issues, however, was the significance their involvement lent to the process of representation. Although it was important for Latino participants to be physically present, it was far less important for them to be politically, intellectually, or philosophically engaged. ${ }^{9}$

Staging and scripting - whether used to maintain the appearance of democracy or repair fissures in this appearance - ultimately serve to reduce (or constrain) avenues for democratic participation while also maintaining organizational efficiency. This is true whether a member chooses to engage, stay silently, or leave (Hirschman, 1971). This study highlights key implications related to both the organizations themselves and, more broadly, to how leaders resolve this conflict between inclusiveness and efficiency. The fact that participants often recognize this tactic, or respond to its effects, suggests that staging and scripting do not work as intended (presumably neither Gretchen nor Helen wanted to lose minority participants). Exit, then is an unintended consequence of the gap between intention and reality. ${ }^{10}$

Internally to the organizations themselves, the qualitative data suggest individual voices are not heard. This is especially true for marginalized communities, whose experiences provide the ethical impetus for movement activity. As a result, agendas do not reflect the core concerns of all. The final effect is thus that people who remain involved under these conditions, either intentionally or as a matter of course, begin to internalize the processes and patterning of staging and scripting and thereby emerge as a follower (Gardner \& Avolio, 1998). Scholars familiar with Lukes' (2004) work on the three faces of power will note that this sequence - silenced voices, closed agendas, internalized perspectives mirrors the ways position is used by those in power. Although most studies have focused on the way this power is used by movement targets (Gaventa, 1982), this study suggests the same process may play out within social movement actors as well.

External impacts include the fact that these strategies force some individuals to leave the group or organization altogether. Those who leave often become engaged in new social 
movement activities elsewhere in the broader organizational field (Diani, in press; see also Rothschild \& Whitt, 1989). Thus, the ways leaders resolve conflicts over inclusiveness and efficiency has a real bearing on the broader trajectory of the social movement field as subsequent activities may have a radical flanking effect. ${ }^{11}$ At this point, we must resist the temptation to impute motives on leaders' behalf. However, it would be useful perhaps to differentiate between intention and skill. The leaders of both groups, I believe, had the intention to create an open and participatory space. Having seen the thankless and challenging tasks these individuals performed without complaint for years (and sometimes decades) on end, it is difficult to imagine that they have done so without some desire for inclusive participation from diverse others. I do not doubt their intentions.

There is room, however, to inquire a bit further into leaders' skill and ability. ${ }^{12}$ Gretchen has been politically active and engaged in leadership positions for progressive causes since the 1970s. Helen, on the other hand, was only recently connected to community organizing efforts, and approached them as a novice. Were this not a comparative study, and I had only observed Helen, then I would have chalked this behavior up to a simple lack of experience. Indeed, it may be that closing conversation with prayer helped manage a discussion that she was unequipped to facilitate, her desire to do so notwithstanding, survival, rather than strategy. This possibility, however, only demonstrates that staging and scripting are useful, or may be thought of by leaders as useful, in a wider range of contexts. Although I have emphasized the tension between efficiency and inclusion, it may very well be that they are used in a much wider range of contexts, and by a much wider array of actors. Indeed, there is reason to expect that such values persist more broadly, in corporate workgroups and academic department meetings, for example. While I leave the question of generalizability to others, recent work by Fligstein and McAdam $(2011,2012)$ emphasizes the similarities of movement and non-movement groups. ${ }^{13}$

It is important to note three interconnected facts about efficiency: (i) there is no one objective definition of efficiency, (ii) efficiencies operate at different levels, and (iii) pursuing efficiencies at one level can lead to inefficiencies at another level. In the majority of the meetings and events I attended, the focus remained on a particular type of efficiency: the goal was to finish meetings on time and with consensus. Yet, there is a difference between tactical and strategic efficiency. In both cases, movement leaders opted for shorter term tactical efficiencies (in managing meetings, for example) rather than on longer term strategic efficiencies (taking more time to ensure authentic buy-in from the Latino community, for example). It is altogether plausible that a better balance between (shorter term) tactics and (longer term) strategies would have had a salutary effect on desired outcomes - e.g. the Coalition might have more efficiently secured the support of the Latino community had it taken more seriously the ideas of Latino members. ${ }^{14}$

This study suggests participants may themselves recognize the use of the tactic, but respond based on an additional set of considerations. For example, those who chose loyalty over exit did so, they told me, because they respected the leaders' sweat equity and commitment. Those who impute other motives, or have a more pressing desire to have their voice heard presumably leave the group, and my sample. While I did not conduct interviews with those who had left the groups, my hunch is that those who left did so for any number of reasons, possibly including a sense of frustration with non-democratic practices. Likewise, I believe those who stayed did so because they either respect the leaders' work, their turf, or perhaps both. 


\section{Conclusion}

Qualitative data provide evidence of the persistence of oligarchic tendencies, even in progressive social movement organizations. This study also suggests a value for democratic organizational forms is rooted in a cultural repertoire that shapes choices regarding organizational form and function. Thus, a tension emerges between the continued commitment to democratic forms and the requirements of organizational efficiency. I suggest organizations may resolve this tension, but in the process undermine democratic commitments and obscure oligarchic realities. Importantly, however, this study suggests oligarchy and democracy are more than just competing cultural ideals, since they are also alternative strategies for moving organizations toward their goals. Both oligarchy and democracy have advantages (efficiency) and disadvantages (apathy, for example), leaders are therefore caught between competing models for operating their organizations. In some cases, selecting between models may represent a sort of existential crisis for groups and their leaders. Such was the case for German environmental groups in the 1980s and 1990s, many of whom found themselves caught between the grassroots' demands of their members, and the new requirements for professionalization within postunification Germany (Markham, 2008; see also Shaiko, 1999). In other cases, the explicit selection of messier democratic forms generates a host of subsequent problems, not the least of which are seemingly endless meetings (Rothschild \& Russell, 1986). Importantly, however, while some groups find professionalization inevitable, and others remain stalwart in their commitment to participatory democracy at any cost, many organizations select a middle path that involves managing the competing tensions between democratic forms and organizational efficiency.

Ethnographic data add microsociological detail on how leaders manage this process. It seems unlikely that leaders in the formal process of adopting more centralized, bureaucratic, and effective forms - or who in the informal process of managing multiple voices and perspectives in small, intentionally inclusive spaces - are simply indifferent to how such shifts may be perceived by their supporters and the general public. Efficiency is not the sole organizational motive. Rather, some leaders may pursue certain democratic practices 'precisely because it spares them the hard work of having to make choices among possible goals' (Clemens, 1993; Polletta, 2002, p. 214). ${ }^{15}$ While participatory democracy may be chosen as a strategy to avoid tough goal setting (Polletta, 2002), this study indicates well-managed democratic-appearing participation may be chosen over forms of leadership perceived to be overly assertive. Either way, social movement actors may fear both inefficiency and strong leadership.

Leaders of such organizations may experience significant (internal and external, implicit and explicit) pressure to produce results while also maintaining an open and inclusive forum for members. Two objectives - efficiency and inclusion - have the potential to clash, ${ }^{16}$ while group members' expectations for a group's ability to meet these objectives may remain fairly constant. This situation may increase a leader's incentive to find a solution that maximizes organizational efficiency while maintaining the appearance of inclusive engagement. This microsociological analysis suggests a balance may be struck through the use of meeting and organizational composition (staging) and talk (scripting).

Finally, it is worth noting that staging and scripting activities may not be limited to smaller organizations. Large and growing organizations may not feel as obligated to pursue inclusive engagement and small, pre-figurative groups may not feel pressured to be 
efficient. It stands to reason that staging and scripting strategies can also be used to perform sociocultural norms other than democracy. The breadth of these strategies were suggested by Meyer and Rowan (1977, p. 357), who observed more than 30 years ago that 'the assumption that formal structures are really working is buffered from the inconsistencies and anomalies involved in technical activities.' Future research may illuminate other areas where leaders experience a tension between a cultural value and the demands of organizational efficiency. There is every reason to expect that this tension exists more broadly, whether in corporate workgroups, academic department meetings or even in right wing movements.

\section{Notes}

1. While democracy is the goal around which staging and scripting occur in this study, it is possible that tensions between other goals can be resolved using the same tactics.

2. The community economic taskforce has a homegrown and volunteerist feel. Meetings occur in community spaces donated by a local non-profit and by a private university where several of the members have ties. Meetings are predominantly attended by middle-class Anglo community members who take time from their personal schedules to participate. The organization sees itself as one of the only organizations holding elected leaders accountable for policy changes, which benefit workers and the poor. Although it is not a stated goal, the community-based economic taskforce provides members a chance to socialize, exchange ideas and engage in solidarity-building efforts to change public policy. Many, if not all, of the participants seem focused on recapturing the essence of the city as it was (or as they remember it): younger, economicallythriving, and confidence-inspiring.

3. The Civil Rights and Immigration issue group working within a faith-based community organizing Coalition. Drawing on the organizing strategies pioneered by Saul Alinksy, the Coalition addresses issues which are said to arise from within its membership. Economic and human resources have been drawn from local places of worship while strategic input is provided by the organization's headquarters. These efforts have resulted in a congregation-oriented organizing campaign whose strategy draws on the support of pastors and priests as individual congregations are organized into voting blocks. As with other community organizing groups, a first phase of mobilization solicited input from congregants. This feedback is then aggregated and narrowed to a specific number of policy demands that are then placed on local political leaders. In this way, ultimate success appears to be measurable movement by policy-makers and local bureaucrats. The second phase, observed in this fieldwork, entails sustaining member's attention to the issues and applying constant pressure on public officials.

4. This variation in experience suggests inexperience as an additional possible motive for staging and scripting. I am thankful to an anonymous reviewer for noting this possibility. It is altogether possible that future research identifies a much wider array of motives, including an explicit desire to exclude certain voices.

5. Michels is insightful here: 'In all the socialist parties there is a continual increase in the number of functions withdrawn from the electoral assemblies and transferred to the executive committees' (1962, p. 72). The division of labor between assembly and executive is hardly problematic. The problem emerges when complex issues are shifted, in an ad hoc fashion, from the former to the latter.

6. I never heard the term consensus defined nor consistently applied in 18 months of fieldwork.

7. For example, the Coalition could serve as a forum for expressing solidarity for this marginalized community or the Latino participants could serve as a potential political fulcrum for the Coalition in its struggles with local politicians.

8. Presumably, one of the reasons Latino members do not understand the group's efforts is poor translation, which Helen admitted the group 'runs out of time to do properly.'

9. Tellingly, in Goffminian terms, such a person is considered to be a 'non-person.'

10. Exit, in fact, may explain why violations of the democratic process are not met with a scene: those who might generate a scene are either loyal (and perhaps voice their concerns on the side) or have left (taking their voice with them).

11. Evidence of this can be seen in the broader context of the community chosen for this study. At the end of my fieldwork, a group of individuals, previously associated with the Taskforce, chose to instead work within the World and US Social Forum movement stream. 
12. I must thank an anonymous reviewer for encouraging me to further develop this possibility.

13. While I believe the leaders in this study used staging and scripting to move a meeting along, there is no reason to believe it cannot also be used intentionally to silence particular communities or intentionally avoid particular outcomes. Anecdotal evidence abounds. When a large meeting of Budapest's taxi company put hundreds of disgruntled drivers face-to-face with the company's president, the event collapsed into a strike. The president responded by appointing a smaller steering committee comprising many supportive votes (to ensure outcomes) and a few outspoken leaders (to ensure legitimacy). Key decisions, however unpopular, subsequently flow from the committee, and can be announced as 'the will of all.' In the end, as one driver explained to me, "he can now say "okay, you elected that advisory group" and escape, because he never has to do a forum where 400 of us can ask him a question.' I am thankful to both anonymous reviewers and the editor for encouraging this line of thinking.

14. I am indebted to an anonymous reviewer for this observation.

15. Witness Gretchen's insistence on agreement at the expense of consensus.

16. Efficiency and inclusion are difficult to balance, though not necessarily mutually exclusive.

\section{References}

Aminzade, R., Goldstone, J., \& Perry, E. (2001). Leadership dynamics and dynamics of contention. In R. Aminzade, J. Goldstone, D. McAdam, E. Perry, W. Sewell, S. Tarrow, \& C. Tilly (Eds.), Silence and voice in the study of contentious politics (pp. 126-154). Cambridge: Cambridge University Press.

Baiocchi, G. (2003). Emergent public spheres: Talking politics in participatory governance. American Sociological Review, 68, 52-74.

Baiocchi, G. (2005). Militants and citizens: Local democracy on a global stage in Porto Alegre. Stanford, CA: Stanford University Press.

Baiocchi, G., Heller, P., \& Silva, M. K. (2008). Making space for civil society: Local democracy in Brazil. Social Forces, 86, 911-936.

Benford, R. D., \& Hunt, S. A. (1992). Dramaturgy and social movements: The social construction and communication of power. Sociological Inquiry, 62, 36-55.

Boekkooi, M., Klandermans, B., \& van Stekelenburg, J. (2011). Quarrelling and protesting: How organizers shape a demonstration. Mobilization, 16, 221-239.

Bordt, R. L. (1997). The structure of women's nonprofit organizations. Bloomington: Indiana University Press.

Bourdieu, P. (1991). Language and symbolic power (J. Thompson, editor; G. Raymond and M. Adamson, Trans.). Cambridge, MA: Harvard University Press.

Clemens, E. (1993). Organizational repertoires and institutional change: Women's groups and the transformation of U.S. Politics, 1890-1920. American Journal of Sociology, 98, 755-798.

Diani, M. (2003). Leaders' or brokers: Position and influence and social movement networks. In M. Diani \& D. McAdam (Eds.), Social movements and networks: Relational approaches to collective action (pp. 105-122). Oxford: Oxford University Press.

Diani, M. (in press). Organizational fields and social movement dynamics. In J. van Stekelenburg, C. Roggeband, \& B. Klandermans (Eds.), The future of social movement research: Dynamics, mechanisms, and processes. Minneapolis: University of Minnesota Press.

DiMaggio, P. J., \& Powell, W. W. (1983). The iron cage revisited: Institutional isomorphism and collective rationality in organizational fields. American Sociological Review, 48, 147-160.

Eliasoph, N., \& Lichterman, P. (2003). Culture in interaction. American Journal of Sociology, 108(4), 735-794.

Epstein, B. (1991). Political protest and cultural revolution: Nonviolent direct action in the 1970s and 1980s. Berkeley: University of California Press.

Ferree, M. M., \& Martin, P. Y. (Eds.). (1995). Feminist organizations. Philadelphia, PA: Temple University Press.

Fligstein, N., \& McAdam, D. (2011). Toward a general theory of strategic action fields. Sociological Theory, $29(11), 1-26$.

Fligstein, N., \& McAdam, D. (2012). A theory of fields. Oxford: Oxford University Press.

Freeman, J. (1972). The tyranny of structurelessness. Berkeley Journal of Sociology, 17, 151-165.

Ganz, M. (2000). Resources and resourcefulness: Strategic capacity in the unionization of California agriculture: 1959-1966. American Journal of Sociology, 105, 1003-1062. 
Gardner, W., \& Avolio, B. (1998). The charismatic relationship: A dramaturgical perspective. Academy of Management Review, 23, 32-58.

Gaventa, J. (1982). Power and powerlessness: Quiescence and rebellion in an Appalachian Valley. Urbana: University of Illinois Press.

Giugni, M., McAdam, D., \& Tilly, C. (1999). How social movements matter. Minneapolis: University of Minnesota Press.

Goffman, E. (1959). The presentation of self in everyday life. New York, NY: Anchor Books.

Hallett, T. (2010). The myth incarnate: Recoupling processes, turmoil, and inhabited institutions in an urban elementary school. American Sociological Review, 75, 52-74.

Hirschman, A. (1971). Exit, voice and loyalty. Cambridge: Harvard University Press.

Leach, D. K. (2005). The iron law of what again? Conceptualizing oligarchy across organizational forms. Sociological Theory, 43, 312-337.

Lee, C. (2007). Is there a place for private conversation in public dialogue? Comparing stakeholder assessments of informal communication in collaborative regional planning. American Journal of Sociology, $113,41-96$.

Lukes, S. (2004). Power: A radical view. New York, NY: Palgrave.

Markham, W. (2008). Environmental organizations in modern Germany: Hardy survivors in the twentieth century and beyond. New York, NY: Berghahn Books.

Martinez, L. (2005). Yes we can: Latino participation in unconventional politics. Social Force, 84, $135-155$.

McCarthy, J. D., \& Zald, J. D. M. (1973). The trend of social movements in America: Professionalization and resource mobilization. Morristown, NJ: General Learning Press.

Meyer, J. W., \& Rowan, B. (1977). Institutionalized organizations: Formal structure as myth and ceremony. American Journal of Sociology, 83, 340-363.

Michels, R. (1915/1962). Political parties. New York, NY: Free Press.

Michelson, M. R. (2005). Meeting the challenge of Latino voter mobilization. The Annals of the American Academy of Political and Social Science, 601, 85-101.

Milkman, R., \& Voss, K. (Eds.). (2004). Rebuilding labor: Organizing and organizers in the new union movement. Ithaca, NY: Cornell University Press.

Minkoff, D., \& McCarthy, J. D. (2005). Reinvigorating the study of organizational processes in social movements. Mobilization, 10, 289-308.

Mouffe, C. (1996). Democracy, power, and the 'political'. In S. Benhabib (Ed.), Democracy and difference (pp. 255-256). Princeton, NJ: Princeton University Press.

Polletta, F. (2002). Freedom is an endless meeting: Democracy in American social movements. Chicago, IL: University of Chicago Press.

Polletta, F. (2006). It was like a fever: Storytelling in protest and politics. Chicago, IL: University of Chicago Press.

Polletta, F., \& Lee, J. (2006). Is telling stories good for democracy? Rhetoric in public deliberation after 9/11. American Sociological Review, 71, 699-723.

Reger, J., \& Staggenborg, S. (2006). Patterns of mobilization in local movement organizations: Leadership and strategy in four national organization for women chapters. Sociological Perspectives, 49, 297-323.

Rothschild, J., \& Russell, R. (1986). Alternatives to bureaucracy: Democratic participation in the economy. Annual Review of Sociology, 12, 307-328.

Rothschild, J., \& Whitt, J. A. (1989). The cooperative workplace: Potentials and dilemmas of organisational democracy and participation. Cambridge: Cambridge University Press.

Rucht, D. (1999). Linking organization and mobilization: Michel's iron law of oligarchy reconsidered. Mobilization, 4, 151-169.

Sampson, R., McAdam, D., MacIndoe, H., \& Weffer, S. (2005). Civil society reconsidered: The durable nature and community structure of collective civic action. American Journal of Sociology, 111, 673-714.

Shaiko, R. (1999). Voices and echoes for the environment: Public interest representation in the 1990s and beyond. New York, NY: Columbia University Press.

Staggenborg, S. (1988). The consequences of professionalization and formalization in the pro-choice movement. American Sociological Review, 53, 585-605.

Staggenborg, S. (1995). Can feminist organizations be successful? In M. Ferree \& P. Martin (Eds.), Feminist organizations: Harvest of the new women's movement (pp. 339-355). Philadelphia, PA: Temple University Press. 
Stepan-Norris, J., \& Zeitlin, M. (2003). Left out: Reds and America's industrial unions. Cambridge and New York: Cambridge University Press.

Smith, J. (2008). Social movements for global democracy. Oxford: The Johns Hopkins University Press.

Swidler, A. (1986). Culture in action: Symbols and strategies. American Sociological Review, 51, 273-286.

Tait, V. (2005). Poor workers' unions: Rebuilding labor from below. Cambridge, MA: South End Press.

Taylor, V. (1989). Social movement continuity: The women's movement in abeyance. American Sociological Review, 54, 761-775.

Taylor, V., \& Van Dyke, N. (2004). "Get up, stand up": Tactical repertoires of social movements. In D. Snow, S. Soule, \& H. Kriesi (Eds.), The Blackwell companion to social movements (pp. 262-293). Malden, MA: Blackwell.

Turner, R., \& Killian, L. (1993). Collective behavior (4th ed.). Englewood Cliffs, NJ: Prentice-Hall.

Voss, K., \& Bloemraad, I. (2011). Rallying for immigrant rights: The fight for inclusion in 21st century America. Berkeley: University of California Press.

Voss, K., \& Sherman, R. (2000). Breaking the iron law of oligarchy: Union revitalization in the American labor movement. American Journal of Sociology, 106, 303-349.

Zald, M. N. (2000). Ideologically structured action: An enlarged agenda for social movement research. Mobilization, 5, 1-16.

Austin Choi-Fitzpatrick is Assistant Professor of political sociology at the School of Public Policy at the Central European University and the American graduate school in Budapest, Hungary. His research focuses on social movements for human rights, with recent publications exploring human trafficking and civil society's use of drones. 